\title{
SICILIA EN PÍNDARO: INSULA FORTUNATA
}

\author{
Emilio Suárez de la Torre \\ Universitat Pompeu Fabra \\ emilio.suarez@upf.edu \\ Ludovico Aegidio, magistro sapientissimo amicoque fidelissimo, \\ nunc in insula fortunata sive in prato florido in aeternum beato, sacrum.
}

\section{RESUMEN}

Análisis de las odas pindáricas dedicadas a vencedores sicilianos, centrado en aquellos rasgos que tienden a una configuración idealizada de sus ciudades y del territorio siciliano.

Palabras Clave: Píndaro, Sicilia, alabanzas, idealización, paisaje.

SICILY IN PINDAR: INSULA FORTUNATA

\section{ABSTRACT}

Analysis of Pindar's odes for Sicilian victors, focusing on those features that create an idealized configuration of Sicilian cities and territory.

KeYwords: Pindar, Sicily, praise, idealization, landscape.

\section{LAS CIUDADES SICILIANAS EN LOS EPINICIOS DE PÍNDARO}

Las ciudades de los destinatarios de los poemas pindáricos, así como las que corresponden a cantos festivos colectivos, se sitúan en lugares muy dispersos del territorio griego, pero hay dos islas que concentran la mayor parte de los mismos: Sicilia y Egina. De los 46 epinicios pindáricos, 15 son para vencedores sicilianos y 11 para eginetas. Dado que mi objetivo es explorar el modo en que los textos destinados a un territorio permiten apreciar una configuración del mismo lo más cerca posible del tema al que se dedica el presente número de la revista, me centraré en las odas destinadas a vencedores sicilianos, ya que las eginetas presentan unos rasgos que, sin dejar de ser peculiares, no permiten establecer un perfil de la isla tan marcado y rico como el que corresponde a Sicilia ${ }^{1}$. En esta revisión agruparé las odas por las ciudades de los vencedores, para concluir con una reflexión sobre el panorama que se desprende de los datos analizados. 


\section{ACRAGANTE}

La relación de Píndaro con vencedores sicilianos fue muy temprana. El año 490 a. C. Píndaro compone dos odas píticas para muy distintos destinatarios y con rasgos un tanto particulares. Así, aunque la Pítica 6 celebra la victoria con el carro de Jenócrates ${ }^{2}$ de Acragante (hoy Agrigento) ${ }^{3}$, el verdadero destinatario de la misma es Trasibulo, hijo de aquél ${ }^{4}$, el mismo al que Píndaro dedicó un encomio (frs. 124 a-b, Snell-Maehler) con un marcado carácter simposiaco 5 . La oda fue entonada en Delfos, como se dice en el proemio ${ }^{6}$, y no faltan en ella rasgos también simposiacos, con una mención inicial a Afrodita y las Gracias que puede a su vez encerrar un eco erótico 7 . Ese mismo proemio reúne la calificación de los Enménidas

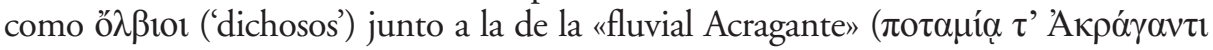
5-6). También en ese comienzo se ensalza cómo la victoria ha permitido erigir un «tesoro de himnos» en Delfos (7-8), con una clara evocación de la arquitectura local, sólo que en este caso el paso del tiempo no puede dañarlo ${ }^{8}$. El conjunto mantiene un tono exhortativo y de algún modo didáctico: recoge el motivo mítico de la muerte de Antíloco ante Memnón, en Troya, por defender a su padre Néstor. Años después (probablemente en el 470), en la Ístmica 2, Píndaro volverá al elogio de esta familia en una oda encargada por Trasibulo en honor de Jenócrates, ya difunto. Será una oda sin relato mítico, pero en la que se hará un catálogo de las victorias de Jenócrates que reflejará su fama panhelénica y en la que asimismo se ensalzará la actividad festiva de los palacios locales, en los que resuenan los cantos (vv. 30-32)9.

La otra oda del 490 es la Pítica 12, dedicada a un vencedor de la competición musical de aulós ${ }^{10}$ en Delfos, Midas, no perteneciente a ninguna de las familias

\footnotetext{
${ }^{1}$ En las odas eginetas los mitos relacionados con la genealogía eácida copan las referencias míticas de casi todas ellas.

${ }^{2}$ Hermano de Terón, hijos ambos de Enesidamo.

${ }^{3}$ Fundada por los de Gela en 580 a.C.

${ }^{4}$ Es posible que Trasibulo fuera el auriga del carro vencedor, a juzgar por el paralelo mítico, aunque no hay certeza de ello.

${ }^{5}$ Véanse las observaciones de Węcowski, 2014: 65-66.

${ }^{6}$ Véase, no obstante, Morrison, 2007: 41-46, quien sugiere que esta evocación délfica está pensada para un auditorio siciliano en el contexto de un simposio organizado por Trasibulo. De hecho el autor ilustra con este poema sus conceptos de "primary audience», «secondary audience» and "terciary audience» (por las sucesivas reinterpretaciones del canto en distintos contextos).

${ }^{7}$ Cf. el comentario de Giannini, 1995: 542, quien recuerda que el único paralelo de mención de Afrodita y las Gracias en un contexto délfico es el Peán 6.

${ }^{8}$ Las imágenes arquitectónicas (en las que suele subrayarse la mayor perduración del canto frente al monumento material) abundan en Píndaro; cf. O. 6,1 ss.; P. 3, 113 s.; P. 7, 3; N. 4, 81; $N$. 8, 46; fr. 194, 1.

${ }_{9}^{9}$ De nuevo Afrodita y la juventud se mencionan al inicio, aunque ya ni Trasibulo ni Píndaro eran precisamente jóvenes.

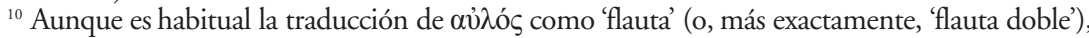
su equivalente más cercano entre los instrumentos posteriores es el oboe.
} 
poderosas de la ciudad. Con adecuación a la modalidad de competición (musical), Píndaro recuerda la invención del instrumento por Atenea con motivo de la victoria de Perseo sobre las Górgonas y la decapitación de Medusa, un relato que ocupa casi el conjunto del poema y que sirve de engarce entre el mito local délfico y la victoria de Midas. La oda se abre con una invocación a la propia ciudad (personificada) que es un elogio de la misma en los siguientes términos:

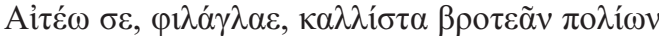

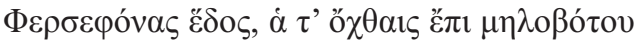

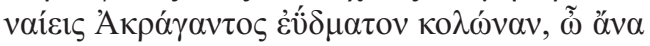

Te pido, amante del esplendor ${ }^{11}$, la más bella de las ciudades mortales, sede de Perséfone, que te levantas sobre la perfecta colina junto a las riberas del Acragante, criador de rebaños, que tú, soberana...

Es notable la precisión de la descripción, si tenemos en cuenta que Píndaro aún no había viajado a Sicilia en esta fecha temprana ${ }^{12}$. La mención de Perséfone es correcta en lo local (por el culto a la diosa) y en la dimensión siciliana, en la que es fundamental el culto a divinidades ctónicas, como veremos después. De nuevo se ensalza el río homónimo de la ciudad, con atribución aquí de su función saludable para sus habitantes ${ }^{13}$.

Sin embargo, las odas más relevantes sobre Acragante y el resto de las ciudades sicilianas corresponden a la década de los años setenta (y posteriores) del siglo $\mathrm{V}$. Tal es el caso de la composición más comentada a propósito de creencias escatológicas y de su significación en el contexto siciliano. Me refiero a la Olímpica 2 (476 a. C.), dedicada a Terón por su victoria con el carro de caballos, en la que encontramos uno de los pasajes pindáricos que han provocado más conjeturas interpretativas (vv. 56-83). Recordemos que en estos versos se establece una clasificación tripartita del destino post mortem sin parangón en el mundo griego, expuesta siguiendo una clara gradación

${ }^{11} \mathrm{O}$ «de la fiesta» (es la significación más frecuente en Píndaro, como puede comprobarse en el léxico de Slater, s.v.). El mismo epíteto es empleado por Baquílides en el Dith. 18 para referirse a Atenas. La presencia de términos formados a partir del radical $\alpha \gamma \lambda \alpha F-$ (que denota en principio 'brillo', 'esplendor') es sustancial en la lírica (véase el volumen de Segal, 1998). En Píndaro encon-

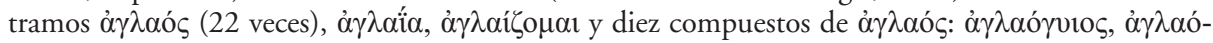

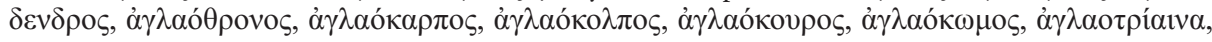
$\dot{\alpha} \gamma \lambda \alpha 0 \chi \alpha i ́ \tau \alpha \varsigma$.

Todas las traducciones corresponden a la versión de Suárez de la Torre, 1988a, con ligeras modificaciones.

${ }^{12}$ Para la cuestión de la presencia o no del poeta en Sicilia y la valoración de sus odas en relación con el contexto histórico y político local, véase Vallet, 1985.

${ }^{13}$ Sobre la importancia de estas menciones paisajísticas en las odas sicilianas, véase Suárez de la Torre, 2010: 47-50. 
desde lo menos positivo a lo más deseable. Primero está el castigo infernal de los «espí-

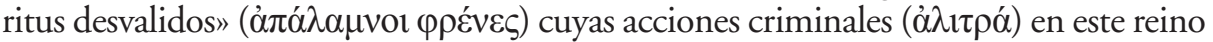

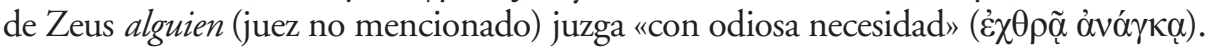
Después se menciona el destino de los $\dot{\varepsilon} \sigma \lambda o$ ó, los cuales, junto a los que fueron fieles a los juramentos, llevan una vida de continua felicidad, libres de esfuerzo para su subsistencia en un grato equinoccio constante. Hasta aquí, nada en este doble destino final choca excesivamente (aunque hay diferencias) con las representaciones griegas tradicionales del Más Allá, al menos en el nivel poético-literario: desde Homero las referencias al destino de los individuos se repartían entre los castigos eternos, la existencia gris de las sombras del Hades y el destino para unos pocos en los Campos Elisios o las Islas de los Bienaventurados, además de la menos prodigiosa pradera de asfódelos (gamones) ${ }^{14}$. El problema viene con la introducción por Píndaro de un grupo que, si bien se hace eco del destino privilegiado homérico para ciertos héroes, lo describe en términos sorprendentes y de difícil encaje en la escatología tradicional:

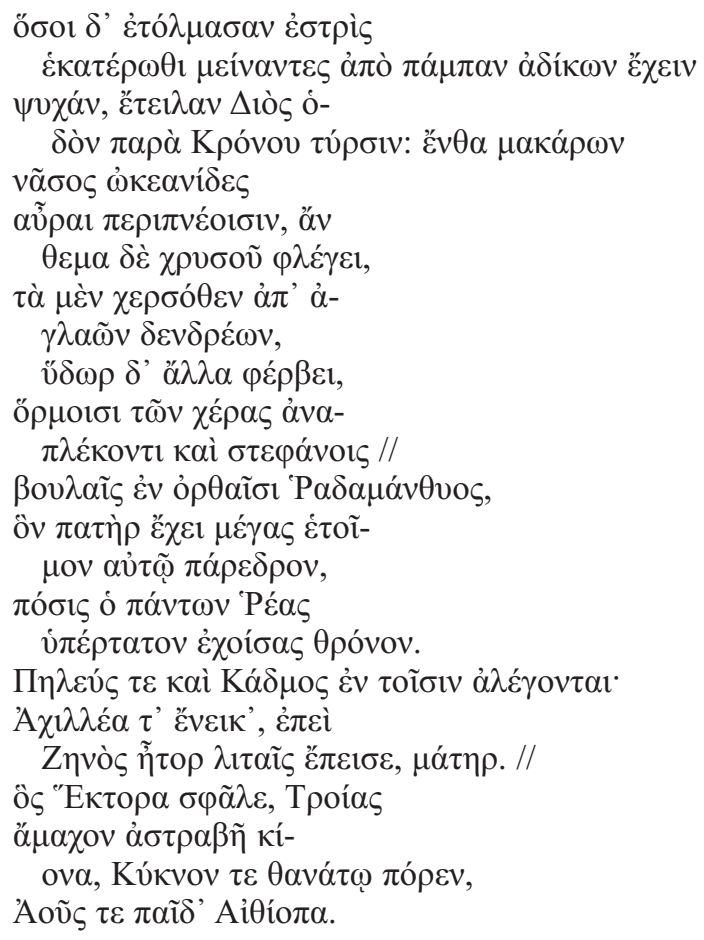

${ }^{14}$ Para la tradición indoeuropea de creación de «paraísos» y su concreción en el mundo griego en la forma de prados, islas beatíficas o el jardín de las Hespérides, $c f$. García Teijeiro, 1985a y 1985b y Velasco López, 1996. La conexión con la concepción del Más Allá que se observa en la documentación órfica fue estudiada por Lloyd-Jones, 1985. 
Y cuantos tienen el valor de permanecer tres veces

en una y otra parte y de apartar por completo de las iniquidades

a su alma, concluyen el camino de Zeus

que lleva a la torre de Crono; allí a la Isla

de los Bienaventurados oceánicas

brisas envuelven. La flor de oro flamea:

unas nacen en tierra firme de espléndidos árboles

y el agua nutre a otras,

con cuyos brazaletes se adornan y trenzan coronas con ellas//

siguiendo las rectas decisiones de Radamantis,

a quien el Padre todopoderoso tiene dispuesto como asesor suyo,

el esposo de Rea, la que ocupa

el trono más elevado de todos.

Peleo y Cadmo entre ellos se cuentan

y a Aquiles allí llevó, cuando de Zeus el corazón

con súplicas persuadió, su madre.//

Él fue quien derribó a Héctor, de Troya

inexpugnable pilar inamovible, y a Cicno envió a la muerte,

y al hijo de la Aurora, al etíope.

Ni que decir tiene que los análisis sobre esta visión del mundo ultraterreno subrayan la relación con las creencias pitagóricas y órficas, aunque es evidente que hay características de difícil equiparación, como la referencia al camino de Zeus hasta la torre de Crono, si bien recientemente se ha visto una posible explicación incluso a este aspecto (Gazis, 2021) ${ }^{15}$. En cualquier caso, es importante insistir en la especial capacidad de Píndaro para adecuar su canto a la persona alabada y a su entorno inmediato y social ${ }^{16}$. Ahora bien, Píndaro no interviene como un mero reproductor de las creencias locales, sino que, a partir de un evidente fundamento en la realidad religiosa coetánea, reconduce lo más sustancial de aquéllas mediante el efecto de ensalzamiento del laudandus y su entorno, con lo que el resultado a la vez es y no es una reproducción literal de lo aceptado por dichas corrientes religiosas. Esa especie de asimilación personalizada y, a la vez, sorprendente, tenía sin duda un fuerte impacto en el auditorio y, como en tantos aspectos de su producción poética, ponía de manifiesto el valor del poeta como intérprete dotado de autoridad religiosa. Además, todo ello implicaba una especial capacidad mimética (lo que no quiere decir fingida)

${ }^{15}$ Por ejemplo, el autor observa que en De caelo 239b 1-6 Aristóteles dice que los pitagóricos se refieren al centro del universo como la $\varphi v \lambda \alpha \kappa \eta$ (el 'puesto de guardia') de Zeus, lo que podría

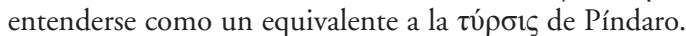

${ }^{16}$ Una prueba del riesgo que implica buscar una coherencia sistemática en Píndaro en la expresión de estas ideas escatológicas la tenemos en el fragmento 58a-b Cannatà Fera (129-130, Snell-Maehler), con la descripción de un Más Allá paradisíaco no coincidente con el aquí descrito. Véase el detallado comentario de la editora (Cannatà Fera, 1990: 163-183). 
en el entorno de Acragante y, en general, siciliano. Es inevitable recordar (y así se ha hecho con frecuencia) la raigambre local del pitagorismo, el orfismo, los cultos mistéricos y las doctrinas empedocleas para entender bien la naturaleza de estas referencias pindáricas. Por otra parte, es evidente que el poeta dispone de un margen de creatividad (en el marco de esa demostración de autoridad poética) que lleva a veces a una desviación espectacular de las tradiciones más conocidas. Es lo que sucede aquí, por ejemplo, con la ubicación de Aquiles (junto a Cadmo y Peleo) en la Isla de los Bienaventurados, incompatible con la versión homérica de la mortalidad del héroe y con la tradición que lo sitúa, inmortalizado, en la Isla Blanca $(\text { Leuke })^{17}$.

Aunque puede parecer conjetural, apunto la posibilidad de que subyazga un paralelo entre Sicilia y la Isla de los Bienaventurados en el sentido de que la conducta de Terón, unida a los valores familiares que aquí se ensalzan y a las creencias de las que el poeta se hace eco, anticipen, como imagen terrena, lo que puede ser el futuro post mortem de aquél y de los seguidores de dichas creencias: un anticipo de la heroización posterior ${ }^{18}$. Incluso prescindiendo de la cuestión de las creencias, fijémonos en la forma en que se elogia a Terón y al hecho de que su genealogía se hace remontar (vv. 46-7) a Cadmo (por cierto, uno de los habitantes de la Isla ${ }^{19}$. La oda comienza con una alabanza de Terón y su familia en la que aquél aparece en la respuesta a la pregunta sobre "¿qué dios, qué héroe, qué hombre celebraremos?» (v. 2) en la que se mantiene esa estructura "tripartita " $^{20}:$ Zeus, Heracles y Terón. A continuación se especifica la razón por la que se justifica esta elección de Terón en esa escala de lo divino a lo humano: sus méritos son la justicia y la hospitalidad (1. 6), su protección de la ciudad, su noble genealogía, que hace de esa dinastía «el ojo de Sicilia», que les debe

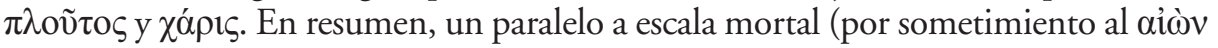
$\mu o ́ \rho \sigma \mu \rho \varsigma)$ que viene a ser el eco de la isla de bienaventuranza luego cantada.

Lo que acabamos de ver en la Olímpica 2 puede completarse con los datos que aporta la Olimpica 3, la cual celebra la misma victoria, pero suele entenderse como un encomio de carácter más público que en el caso de la oda anterior, que parece destinada a un entorno simposiaco. En este caso la oda no contiene referencias locales, pero entrelaza la victoria olímpica y la victoria de Terón de una manera muy directa,

${ }^{17}$ Cf. Gazis, 2021: 117, n. 46: «This simple reference succeeds in intertwining two incompatible traditions: that of Achilles's mortality as depicted in both the Iliad and the Odyssey, and that of his immortal fate as it appears in the Cycle».

${ }^{18}$ Píndaro deja claro que Aquiles merecía un destino eterno en aquél paraíso, al que es transportado gracias a las súplicas que Tetis dirige a Zeus, decisión en la que pesa la triple hazaña de Aquiles al dar muerte a Héctor, Cicno y Memnón. La isla tiene dos rasgos manifiestos: las brisas oceánicas y los frutos de oro que surgen de sus árboles y aguas, usadas para hacer joyas y coronas. Todo ello bajo el recto juicio de Radamantis.

${ }^{19}$ Sobre la importancia de la perspectiva genealógica en las odas pindáricas véase Suárez de la Torre, 2006; sobre este pasaje concreto $c f$. Catenacci, 2013: 47-48.

${ }^{20}$ Se ha llegado a hablar incluso de una «mística del número 3» en esta oda: Newman, 1984: 143. 
en la que la ascendencia doria de la familia está implícita en el recuerdo de la institución de los Juegos por Heracles al regreso de su conquista de la cierva de Cerinías (uno de los trabajos encargados por Euristeo). El núcleo de esta rememoración mítica es el recuerdo que Heracles tenía de la riqueza en bosques del país de los Hiperbóreos, territorio apolíneo con rasgos paradisíacos ${ }^{21}$. En Olimpia no había árboles y el héroe retorna a las regiones hiperbóreas del Istro para traerse aquella vegetación (los olivos) que en su viaje precedente tanta admiración le había causado: $\tau$ ó $\theta 1$

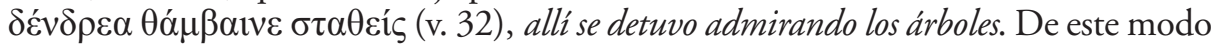
el territorio regado por el Alfeo obtuvo la protección frente al ardiente sol. Entonces Heracles estableció allí a los tindáridas (mencionados al comienzo del poema) como patronos de los juegos. De modo que en este epinicio quedan unidos la genealogía mítica, los Hiperbóreos, Olimpia y la victoria de Terón a través de un canto cuyos rasgos compositivos (e innovadores) son detallados por el poeta, al insistir en el ajuste de

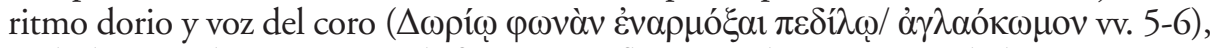
melodía, sonido instrumental (forminge y flautas) y disposición verbal (

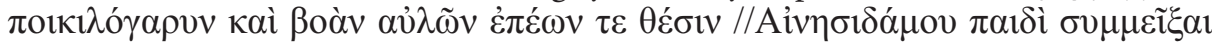
$\pi \rho \varepsilon \pi \delta ́ v \tau \omega \varsigma$ vv.8-9).

\section{SIRACUSA}

La familia de los Dinoménidas ${ }^{22}$ y, en especial, Hierón, hizo de esta ciudad uno de los centros de poder político y, a la vez, culturales, más destacados de su época ${ }^{23}$. Numerosos poetas acudieron a la corte del tirano, aparte de Píndaro, como Simónides, Baquílides o Esquilo. En ese contexto, Píndaro dedica a Hierón algunas de sus más elaboradas composiciones, entre las que destaca la Olímpica 1 (del 476 a. C.), por su victoria en la carrera de caballos. Es posible que hubiera un canto de victoria en Olimpia, pero esta oda tiene rasgos que la hacen adecuada para un entorno simposiaco, en una celebración siracusana ${ }^{24}$. De nuevo el poeta hace de Olimpia y sus mitos

${ }^{21}$ El país de los Hiperbóreos es mencionado por Píndaro, además de en este pasaje, en $P$. 10, 30, I. 6, 23 y Pae.8, 63. Este territorio lejano septentrional estuvo siempre ligado a Apolo: va allí después de su nacimiento y es el lugar al que se desplaza en invierno, cuando Dioniso permanece en el santuario; cf. Piquero, 2012, con análisis de los ritos que enlazan con la isla de Delos. Véase asimismo Suárez de la Torre, 2013 y 2015. Una relación entre este mito y la idealización de los celtas ha sido propuesta por Marco, 2000.

${ }_{22}^{22}$ Para la historia de las tiranías sicilianas y sus vicisitudes, véase Luraghi, 1994.

${ }^{23}$ Importante estudio de la evolución de la tiranía siracusana en Morgan, 2015.

${ }^{24} C f$. Morrison, 2007: 57-65. En relación con la cuestión de las reinterpretaciones en diversas ocasiones y contextos de las odas pindáricas, véase asimismo Currie, 2004. Para el contexto simposiaco es importante Athanassaki, 2016. Más allá de Píndaro, el análisis de la evolución y función del simposio en la sociedad griega antigua (fundamentalmente en relación con la interpretación lírica) cuenta con importantes estudios, de los que ahora menciono sólo algunos: Bowie, 1986, Murray, 1990, Vetta, 1995², Hobden, 2013, Węcowski, 2014 (perspectiva histórica), Romney, 2020. 
el núcleo de la composición, pero siempre con una estudiada vinculación (mediante paralelos y alusiones) al vencedor y sus cualidades dignas de elogio. Ya al inicio de la oda se ensalza el valor excepcional de la competición olímpica frente a las demás, por lo que el epinicio se convierte en sustancial para difundir la gloria de Hierón ${ }^{25}$. Ello permite entonar el himno a Zeus «al llegar al hogar bienaventurado de Hierón, quien ostenta el cetro dictaminador en la fructífera /Sicilia, recolectando los capullos de todas las virtudes,/ mientras resplandece a la vez/ en lo más exquisito del arte musical/ con diversiones como las que nos reúnen/ a los hombres con frecuencia alrededor de su mesa hospitalaria ${ }^{26}$. Las referencias a Hierón rozan el tono heroico

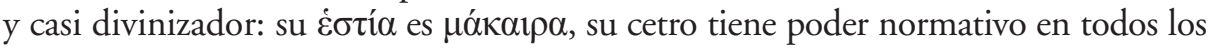
aspectos $(\theta \varepsilon \mu 1 \sigma \tau \varepsilon i ̃ o v ~ \sigma \kappa \alpha \tilde{\tau} \tau o v)^{27}$, más allá de Siracusa, con adición de un adjetivo

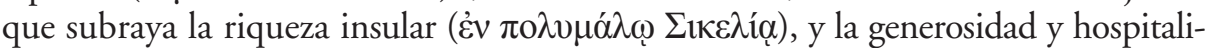
dad de Hierón se confirman con los frecuentes banquetes, que dan esplendor a su pala-

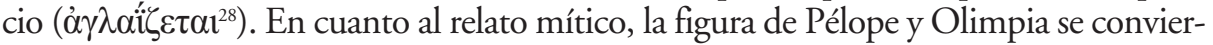
ten en su centro y el poeta enlaza la victoria mítica del héroe con la actual con insistencia en la protección divina que permitió que aquélla tuviera lugar ( $c f .61-93)$.

De fecha dudosa (se ha propuesto el 475, el 470 e incluso el 468 a. C. $)^{29}$ es la Pítica 2, de nuevo dedicada a Hierón por una victoria con el carro. Es una oda que encierra bastantes elementos exhortativos contra la falsedad y a favor de una conducta recta y sin excesos. El modelo mítico ejemplar (en sentido negativo y rechazable) es el de Ixión, mito central de la composición. Ese ejemplo negativo se completa con las menciones positivas de Cíniras y de Radamantis, dos paralelos positivos con la figura de Hierón, el segundo de los cuales vuelve a aparecer en la descripción escatológica de Olímpica 2. El rasgo más notable de esta oda es la absorción de rasgos

${ }^{25}$ En realidad, el canto de victoria establece un perfil heroico del vencedor. $C f$. Pòrtulas, 1985.

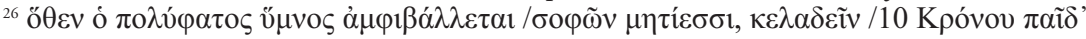

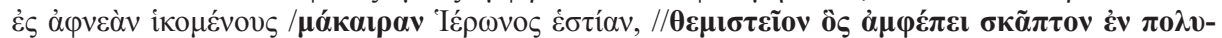

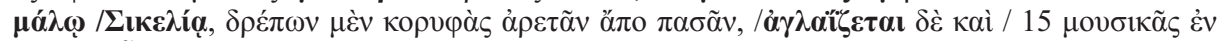

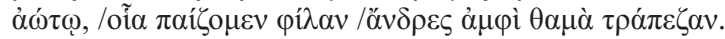

${ }^{27}$ Véase Morgan, 2015: 227 acerca de la relación que subyace entre la mención del cetro de Agamenón, de Pélope y de Hierón: «If we are alive to this resonance of Agamemnon's scepter, it is tempting to conclude that conceptually Hieron's scepter is Pelops' and Agamemnon's scepter, and descended to all of them from Zeus. In Iliad 2.104, the scepter was given by Hermes to Pelops, the "driver of horses,» and he in turn gave it to Atreus, the «shepherd of the people» (2.105). No wonder Hieron wields the scepter of justice in Sicily, rich in flocks, and in line 23 delights in horses. Evidently, the flocks are not only sheep».

${ }^{28}$ De nuevo aparece la relación entre el término $\alpha \gamma \lambda \alpha$ ó $\varsigma$ lo festivo. De hecho, la acumulación en esta oda de epítetos y términos que subrayan la gloria y la felicidad en torno a Hierón, según señala Sigelman, 2016: 181 confirman que «the symposium is thus the here and now within which the greatest praise of the greatest victor at the greatest of contests is about to resound».

${ }^{29}$ Discusión de las diversas propuestas (y sobre la victoria que en concreto es aquí cantada) en Cingano, 2013: 44-47, quien se inclina por una victoria con el carro de caballos o bien en el 470 en Delfos o bien en el 468 en Olimpia (con preferencia por esta segunda opción). 
propios de la poesía arquiloquea, reconducidos en este elogio del comitente de manera muy elaborada ${ }^{30}$. En este caso no hay referencias concretas notables sobre Siracusa o Sicilia, con la excepción del comienzo, ya que se abre con una invocación a la ciudad ( $\mu \varepsilon \gamma \alpha \lambda \circ \pi$ ó $\lambda \iota \varepsilon \varsigma \tilde{\omega} \Sigma v \rho \alpha ́ \kappa o \sigma \alpha 1$, en la que se pone de relieve su poder militar $(\beta \alpha \theta v-$

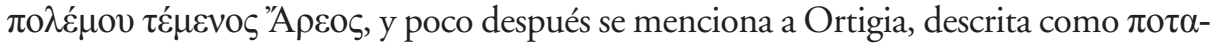

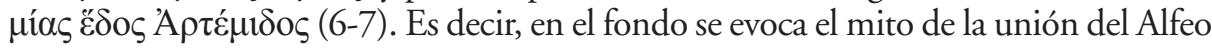
con Aretusa, como veremos en la Nemea 1, que a su vez justifica la veneración de Ártemis como protectora de ésta. También se destaca la especial protección de Ártemis, Hermes y Posidón en esta variedad ecuestre (9-12).

La Pítica 3 (quizá del 474) no es estrictamente un epinicio o, más exactamente, no puede vincularse a una victoria concreta. El tono de la misma es, desde luego, encomiástico hacia Hierón, pero también encierra una faceta consolatoria (Young, 1968: 27-68, Slater, 1988). Se articula en dos partes que van encabezadas por la mención del centauro Quirón, debido a su educación de Asclepio. En la primera parte se evoca precisamente el mito del nacimiento de Asclepio. Se menciona la unión de Corónide con Apolo y su muerte a manos de él, por haberse atrevido a unirse a un mortal estando embarazada del dios. Éste rescata de la pira ${ }^{31}$ a su hijo y lo entrega a la crianza y educación de Quirón. Las cualidades médicas de Asclepio son destacadas con detalle, pero de nuevo el mito sirve para ilustrar una ofensa a los dioses: la de haberse atrevido a resucitar a un muerto, lo que conduce al castigo correspondiente. Una segunda mención de Quirón abre la segunda parte, con referencias a la actividad del poeta y de nuevo a su deseo de aportar consuelo y curación a Hierón. Píndaro introduce entonces diversas referencias míticas, con menciones de las bodas de Tetis y Peleo, de Cadmo y sus hijas y Aquiles, con reflexiones sobre lo cambiante del destino, y, por último, Néstor y Sarpedón, para subrayar la virtud de inmortalización que posee el canto.

La Olimpica 6, ya del 468, se dedica a Hagesias de Siracusa (vencedor con el carro de mulas), descendiente de los Yámidas por línea materna, encargados del altar mántico de Olimpia ${ }^{32}$. La figura de los adivinos es la fundamental en el tratamiento del mito, primero con la mención de Anfiarao (al que Hagesias de algún modo es equiparado) y luego con el mito central, que es el del nacimiento y consagración como adivino de $\mathrm{Iamo}^{33}$. La ciudad de Estínfalo, en Arcadia, es de donde procede la madre de Hagesias, y Píndaro busca incluso la forma de enlazar esta genealogía con su propio origen tebano (vv. 84-86). A partir de ahí el poeta pasa a la mención de la ciudad en estos términos:

${ }^{30}$ Estudio detallado de estos rasgos en Suárez de la Torre, 1992.

${ }^{31}$ Colabella, 2021: 153-155 considera que las repetidas menciones de las piras de fuego y de los vientos se relacionan con Zeus y que existe un nexo con la Pítica 1. La propuesta es interesante, pero el problema sería saber si el público apreciaba esa relación.

${ }_{32}^{32}$ Véase Luraghi, 1997.

${ }^{33}$ Para la presencia del motivo mántico en Píndaro, véase Suárez de la Torre, 1988b, 1989, 1990. 


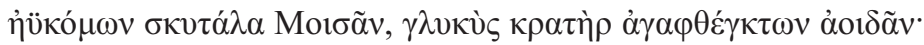

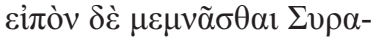

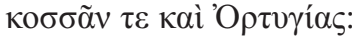

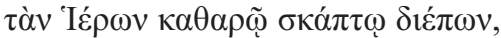

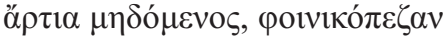

$\dot{\alpha} \mu \varphi \varepsilon ́ \pi \varepsilon 1 \Delta \alpha \dot{\alpha} \mu \alpha \tau \rho \alpha, \lambda \varepsilon v-$

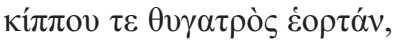

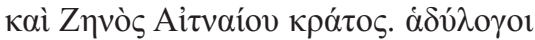

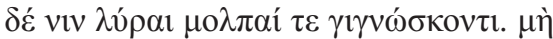

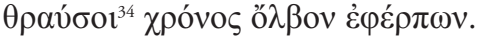

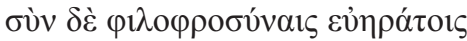

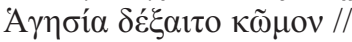

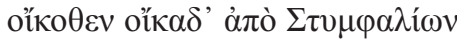

$\tau \varepsilon \imath \chi \varepsilon ́ \omega \nu \pi 0 \tau \imath v 1 \sigma \sigma o ́ \mu \varepsilon v o v$,

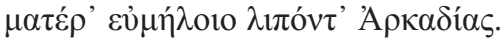

Diles que se acuerden de Siracusa y de Ortigia;

por ella vela con inmaculado cetro Hierón,

con cabal juicio, y rodea de cuidados

a Deméter, la del calzado púrpura,

a la fiesta de su hija, la de los blancos caballos

y al poder de Zeus Etneo. La dulce voz

de las liras y de los cantos lo conocen.

¡Que el tiempo, en su reptar, no turbe su dicha

y que él, con afectuosas muestras de cariño,

acoja al cortejo de Hagesias, //

al volver desde las murallas de Estínfalo,

de patria a patria,

tras dejar atrás a la madre de Arcadia, en ovejas rica!

El relato mítico y las referencias genealógicas y a la actualidad construyen un sólido puente entre los territorios griegos del Peloponeso y Sicilia, subrayado con gran precisión en la expresión oű́o $\theta \varepsilon v$ oľk $\alpha \delta(\varepsilon)$. No deja el poeta de involucrar a Hierón en el elogio, con la nueva mención de Siracusa y de Ortigia ${ }^{35}$.

\section{ETNA}

La consideración aparte de odas a «etneos» no tiene otra justificación que la adecuación a la asignación que las propias odas nos muestran en cuanto a la ciudad

${ }^{34}$ Sigo la lectura de la edición de Gentili, 2013.

${ }^{35}$ Para la relación de esta oda con la Nemea 1, cf. Colabella, 2021: 160 con referencias. 
a la que el vencedor parece vincularse. Como es sabido, la ciudad de Etna se corresponde en realidad con la antigua Catania, de la que sus primeros habitantes fueron expulsados por Hierón, quien consideró la repoblación y reconstrucción de la ciudad como una "fundación». Por otra parte, la mención de Zeus Etneo podría indicar que su entonación se hizo en el festival dedicado a él (Cannatà, 2020: 15-17). Las odas a tener en cuenta son las siguientes.

La Nemea 1, de datación problemática ${ }^{36}$, está dedicada a la victoria de Cromio con el carro de caballos. La estructura de la oda es sencilla, ya que la primera parte se dedica al elogio de la victoria y la segunda al mito del prodigio de Heracles nada más nacer, al dominar a las tres serpientes enviadas por Hera, y a las profecías que emitirá Tiresias sobre su futuro. La mención de Heracles es apropiada para establecer un vínculo con el territorio de Nemea, aparte del habitual paralelo subyacente entre el héroe y el vencedor. Por otra parte, en el comienzo de la oda Píndaro introduce varias referencias que configuran una visión de Sicilia como territorio bajo protección divina. Píndaro recuerda un motivo mítico que enlaza Sicilia (y Siracusa en concreto) con el Peloponeso, al aludir a la unión del río Alfeo con Aretusa, transformada en fuente por Ártemis para evitar el acoso del río. La isla de Ortigia es evocada como el «brote» del que nace Siracusa:

"А $\mu \pi v \varepsilon v \mu \alpha \sigma \varepsilon \mu \nu$ òv 'A $\lambda \varphi \varepsilon \sigma \tilde{v}$,

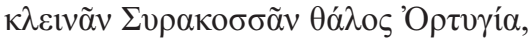

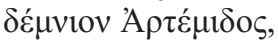

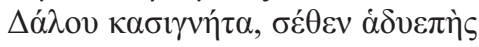

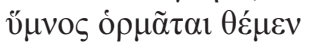

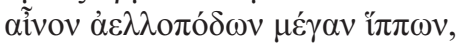

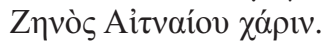

Aliento venerable del Alfeo,

Ortigia, brote de la ilustre Siracusa, lecho ${ }^{37}$ de Ártemis,

hermana de Delo, al himno de dulce verbo

sirves de motivo para componer

notable elogio de los corceles

de patas de huracán, gozo de Zeus Etneo.

A continuación se recuerda que Sicilia es patrimonio de Perséfone, gracias a Zeus. El poeta ha de hacer resplandecer (de nuevo ỏ $\gamma \lambda \alpha i ̂ ́ \alpha)$ con su canto la riqueza natural de la isla, con una estrecha relación entre la fertilidad de su suelo y la prosperidad de sus ciudades. de Etna.

${ }^{36}$ Cf. Presutti, 2021. Entre las fechas propuestas está la del 476 a. C., año de la fundación

${ }^{37}$ Equivalente a 'morada'. Cf. Cannatà, 2020: 265. 


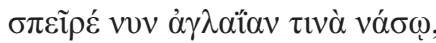
$\tau$ $\alpha े v^{\prime} \mathrm{O} \lambda \hat{\mu} \mu \pi \mathrm{ov} \delta \varepsilon \sigma \pi \mathrm{\tau} \tau \alpha \varsigma$

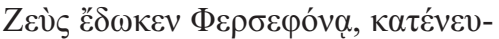

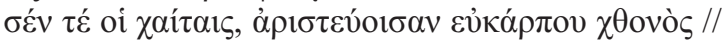

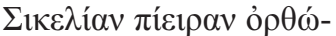

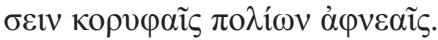

Siembra tú ahora esplendor

para la isla que el amo del Olimpo,

Zeus, concedió a Perséfone, cuando con la agitación de su cabellera

asintió a que encumbrara a la pingüe Sicilia//,

la mejor por la fertilidad de la tierra,

con la riqueza cimera de sus ciudades.

La otra oda dedicada a Cromio es la Nemea 9, incluida en la transmisión textual pindárica como tal, pero que no celebra una victoria en Nemea, sino en Sición, en un festival dedicado a Apolo. En este caso Etna está explícitamente mencionada como "recién fundada»" (eso fue en el 476, por lo que la victoria debió de ser hacia el 475 o 474 a.C.). Esa victoria queda enlazada con el mito de Anfiarao y los siete, que llena la primera parte de la oda, con llamadas a la prudencia e incluso una exhortación a mantenerse en guardia ante la posible amenaza cartaginesa ${ }^{39}$, pero con el ruego a Zeus de que conceda «la fortuna del justo gobierno duradero a los hijos de los Etneos» ${ }^{40}$ y de que la ciudad mantenga su actividad festiva pacífica ${ }^{41}$. El poeta señala que los ciudadanos de Etna «aman los caballos y su espíritu está por encima de las riquezas» ${ }^{42}$. Tras una exhortación de tono bélico, se establece un paralelo entre el combate de Héctor a orillas del Escamandro y de Cromio junto al Heloro, donde se produjo en 492 a. C. una confrontación de los de Gela, al mando de Hipócrates, contra los siracusanos (que fueron derrotados), en la que participó Cromio. En composición anular, la última parte insiste en el elogio de la victoria y en el simposio de celebración.

La victoria de Hierón con el carro en el 470 a. C. se conmemora en la Pítica 1, una de las más logradas composiciones pindáricas. Tras la apertura con la descripción de los efectos positivos de la música, capaces de hacer dormitar al águila de Zeus (una imagen con un paralelo subyacente del poder divino y del de Hierón), se introduce una larga mención del volcán Etna y del mito de la presencia de Tifón castigado

${ }^{38} \mathrm{O}$ sea, más bien «refundada».

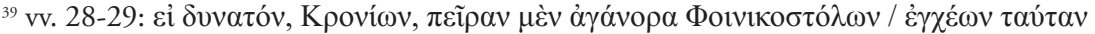

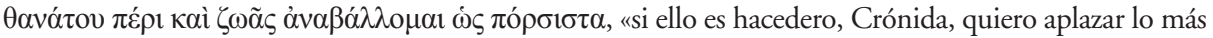
posible / esa violenta prueba ante las lanzas de las púnicas expediciones, que será a vida o muerte». Sobre la particularidad de esta expresión de aplazamiento, $c f$. el comentario de Cannatà, 2020: 524.

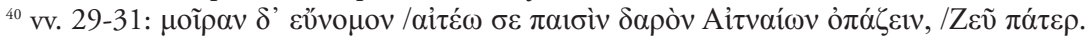

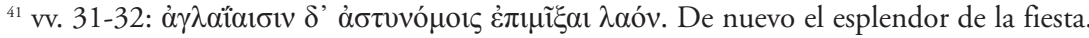

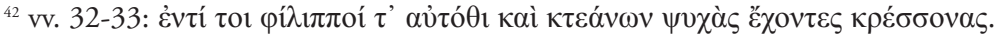


y oprimido en sus profundidades, causa de las erupciones ${ }^{43}$. Es un ejemplo de castigo de la hostilidad a Zeus, que sirve asimismo de advertencia contra la ofensa y hostilidad hacia el propio Hierón. Frente al castigo de Tifón, Zeus protege al gobernante, del que se evoca la fundación de la ciudad homónima del volcán en estos términos:

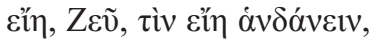

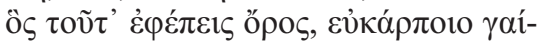

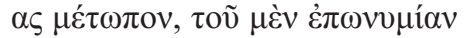

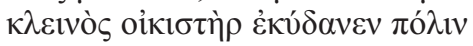

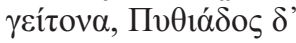

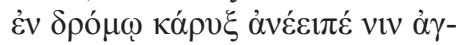

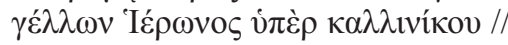

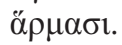

Que sea posible, Zeus, que sea posible agradarte,

a ti, soberano de este monte, prominencia de una

fructífera tierra, cuya ciudad vecina, de igual nombre, su ilustre fundador honró:

en la carrera de los juegos Píticos el heraldo

la anunció en su proclama, gracias a Hierón,

que logró bella victoria //

con su carro.

Luego, tras la referencia a su labor poética, Píndaro introduce la evocación del héroe Filoctetes, sin cuyo arco no se tomaría jamás Troya. Fue, pues, imprescindible, como Hierón lo es para defender y derrotar a los enemigos de Sicilia. Esta evocación se enlaza con la mención del gobernante de Etna, Dinómenes, hijo de Hierón. La unión con el territorio dorio se hace mediante el recuerdo de sus antepasados los Heraclidas, para volver de nuevo a subrayar la capacidad guerrera y pacificadora de Hierón, del que se ensalzan sus victorias sobre los cartagineses en el 480 a. C. y sobre los etruscos en el 474 (en Cumas), acciones puestas en paralelo encomiástico con la victoria sobre los persas ( $c f$. vv. 70-80).

\section{CAMARINA}

La historia de Camarina en los siglos VI y V a. C. estuvo marcada por las disputas entre Siracusa y Gela. Siracusa la funda en el 598 a. C., pero en el 553 se produce una rebelión contra los siracusanos que acabó en su destrucción, hasta que

${ }^{43}$ Véase el afinado comentario de Elliger, 1975: 207-208 sobre la descripción de la erupción. Sobre la significación de la referencia al Etna y Tifón, $c f$. Colabella, 2020: 145 (y vid. supra observación en n. 31). 
Hipócrates de Gela la «refunda» en el 493 a. C. Sin embargo, Gelón expulsó a sus habitantes en 485 a. C. y volvió a destruir la ciudad. Su nueva «refundación» se produce en los años sesenta del mismo siglo, cuando los de Gela proceden de nuevo a su reconstrucción. Estas vicisitudes complican la datación de las odas dedicadas a Psaumis de Camarina (Olimpica 4 y Olimpica 5), sobre todo por el hecho de que en Ol. 5, 8-8a se habla de la proclamación que hizo el heraldo del padre de Psaumis, Acrón, en la que se incluía asimismo $\tau o ̀ v v ~ v \varepsilon ́ o t \kappa o v ~ \varepsilon ̌ \delta \rho \alpha v$, adjetivo que puede entenderse como 'de reciente construcción' o simplemente 'reconstruida'. La discusión sobre este punto es larga ${ }^{44}$. Aunque no es fácil adoptar una opción segura, remito a la razonada propuesta de Liana Lomiento ${ }^{45}$ quien, tras un análisis exhaustivo de los datos, concluye con una probable datación alta de la Olimpica 5 (488 a. C.) y una mucho más reciente de la Olimpica 4 (452 a. C.).

Ambas tienen en común su brevedad y la presencia mínima de referencias míticas. En la Olímpica 5, que comienza con una invocación a la ninfa Camarina, se hace un elogio del vencedor como benefactor de la ciudad que incluye referencias geográficas locales:

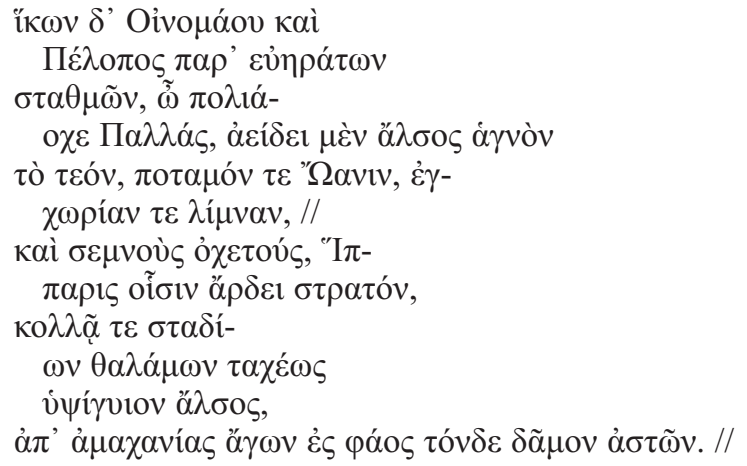

Al llegar de la amable morada de Enómao y Pélope, ¡Palas, que la ciudad sustentas!, canta a tu bosque santo, al río Óano, a ti dedicado, a la local laguna

y a los venerados canales con los que el Híparis da sus riegos al pueblo

y consolida velozmente el bosque de altos miembros de los firmes edificios, mientras conduce a los ciudadanos de este pueblo de la miseria a la luz.

Una vez más la unión del lugar de la victoria con la ciudad del vencedor se materializa a través del ensalzamiento de los rasgos del territorio: la morada de Enómao y Pélope se vincula con el canto al bosque y a los elementos fluviales de

${ }^{44}$ La datación admitida hasta ahora, nada segura, era del 460 o 456 a. C. para ambas, incluso con la suposición de que correspondían a una misma victoria.

${ }^{45}$ Lomiento, 2013: 99-102 y 113-120. 
Camarina. Además, se hace una alusión a la labor de reconstrucción y repoblación de Psaumis, con la expresiva imagen del paso de la impotencia a la luminosidad ${ }^{46}$. En la brevísima Olímpica 4 no falta tampoco una referencia a las cualida-

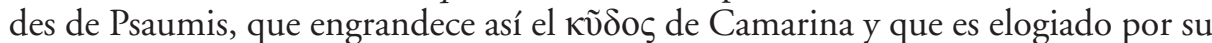

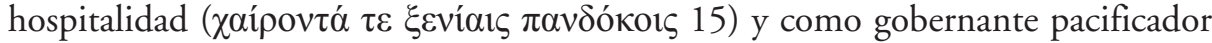

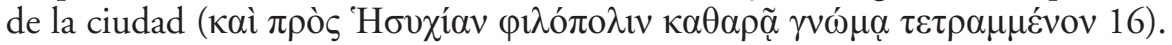

\section{HÍMERA}

La particularidad de la Olímpica 12 es que está dedicada a un ciudadano de Hímera, Ergóteles, que procedía de la cretense Cnoso, de donde escapó de las revueltas civiles para ser acogido en la ciudad siciliana, probablemente en el 476/5 a. C., cuando Terón "repuebla» la ciudad después de la sangrienta represión del intento de Terilo por restituir la influencia cartaginesa (Catenacci, 2013: 288). Probablemente la oda ha de datarse en el 470 a. C., aunque no se puede excluir el 466 . Esta breve composición presenta una primera parte en que se hace referencia a Tyche, la Fortuna, y a las cambiantes circunstancias que pueden sobrevenir en la vida, lo que es adecuado, sin duda, a los acontecimientos vividos tanto por el laudandus en su patria como a los que se sucedieron en el entorno de Hímera en esas décadas. Píndaro subraya que el haber tenido que partir de Creta en realidad ha sido un acontecimiento que le ha permitido coronarse como vencedor en los Juegos deportivos y ganar gloria panhelénica y no sólo local. En cuanto a las referencias locales, al final del canto el poeta ubica la nueva vida del vencedor junto a los baños termales de las Ninfas en Hímera ${ }^{47}$,

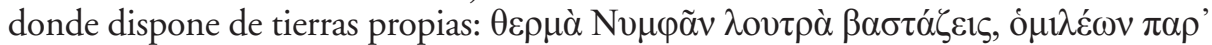
oíkzíaıs àpoúpaıs. De nuevo un paisaje local con una referencia cultual contribuye a la creación de una imagen idealizada del entorno del vencedor.

\section{OBSERVACIONES A PARTIR DE LOS DATOS ANTERIORES}

Las odas comentadas presentan una lógica variedad en sus características debida a la diversidad de sus destinatarios y a las circunstancias en que tiene lugar la victoria (referentes tanto a la persona y su genealogía como al momento histórico y la situación política y social). A pesar de esta limitación y mediante su especial habilidad poética, Píndaro consigue lo siguiente:

a) A partir de la personalidad del vencedor, configura un panorama de las ciudades sicilianas como receptáculos de virtudes míticas que quedan actualizadas

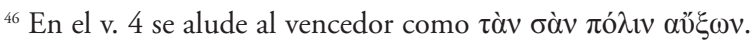

${ }^{47}$ Sobre este culto y la importancia local de estos baños véase el análisis de MacLachlan, 2021. 
por vía genealógica o mediante el paralelo mítico. Entre ellas destacan la generosidad (que tiene especial reflejo en la hospitalidad y organización festiva), la capacidad de gobierno justo y de defensa de los ciudadanos y del territorio. La idea esencial que transmiten todos estos aspectos es la de paz y seguridad para los ciudadanos que escuchan los elogios, incluso a partir de hechos o circunstancias no fáciles de convertir en algo positivo: hasta el terrible Etna sirve de argumento favorable.

b) En el elogio de la ciudad del vencedor predominan dos factores. Primero, los elementos que hacen de ella un entorno próspero y fértil. En ello tienen un peso especial las menciones de ríos y fuentes, de la riqueza en ganado, etc. En este apartado cabe destacar la mención de la unión del Alfeo con Aretusa (N. 1), ya que, más allá del prodigio mítico rememorado, supone la materialización mítica de la vinculación de la isla con el territorio de las victorias deportivas, además de hacer de Ortigia una "gemela» de la isla de Delos (mediante la figura de Ártemis). Incluso más allá de lo meramente fluvial, el volcán Etna, con el culto a Zeus Etneo, transforma una realidad geológica amenazante en un símbolo del poder divino y de su protección a Sicilia. En segundo lugar, y aunque no es un rasgo exclusivo de estas odas, hay que sumar a lo dicho la insistencia en las cualidades hospitalarias de los vencedores, que contribuyen a crear un entorno de esplendor y felicidad en lo inmediato y de prosperidad para todo el territorio. Como es lógico, en esta particular configuración de la Sicilia pindárica ocupa un lugar especial el relato de la Olímpica 2 sobre la Isla de los Bienaventurados y su original contenido escatológico, con todas sus posibles connotaciones.

Es evidente que este panorama siciliano no corresponde a ningún programa encomiástico específico del poeta, sino que es la suma de los diversos perfiles que se obtienen de las descripciones, referencias y relatos que encontramos en las odas pindáricas. Esa suma da como resultado una imagen de Sicilia que nos permite calificarla de Insula Fortunata: sin duda los ciudadanos que asistieron a cada una de esas celebraciones (y los que pudieron escuchar esos poemas en ocasiones posteriores ${ }^{48}$ ) podían compartir en esos momentos el sentimiento de esplendor que se desprende de esas odas.

\section{REFERENCIAS BIBLIOGRÁFICAS}

Athanassaki, L. (2016): "The Symposion as Theme and Performance Context in Pindar's Epinicians», en Cazzato, V. - Obbink, D. - Prodi, E. E. (eds.), The Cup of Song. Studies on Poetry and the Symposion, Oxford University Press, Oxford, pp. 85-112.

BowIE, E. (1986): «Early Greek Elegy, Symposium, and Public Festival», JHS 106: 13-35.

Cannatà Fera, M. (1990): Pindarus. Threnorum Fragmenta, Ateneo, Roma.

Cannatà Fera, M. (2020): Pindaro. Le Nemee, Fondazione Lorenzo Valla, Arnoldo Mondadori Editore, Milano.

${ }^{48}$ Remito de nuevo a Currie, 2004 y Morrison, 2007. 
Catenacci, 2013, vid. Gentili-Catenacci-Giannini-Lomiento.

Cazzato, V. - Obbink, D. - Prodi, E. E. (eds.) (2016): The Cup of Song. Studies on Poetry and the Symposion, Oxford University Press, Oxford.

Cingano, 2013, vid. Gentili-Bernardini-Cingano-Giannini.

Colabella, S. (2021): «Aitna and Typho's Myth as a Poetic Paradigm», en Reid, H. L. - LeWIS, V. M. (eds.), Pindar in Sicily, Fonte Aretusa Organization, Parnassos Press, Sioux City, Iowa, pp. 143-164.

Currie, B. (2004): «Reperformance Scenarios for Pindar's Odes», en Mackie, C. J. (ed.), Oral Performance and its Context, Brill, Leiden/Boston [Orality and Literacy in Ancient Greece, vol. 5], pp. 49-69.

ELLINGER, W. (1975): Die Darstellung der Landschaft in der griechischen Dichtung, Walter de Gruyter, Berlin/New York.

Epstein, N. S. (2021): «Synoptic Sicily: Pindar and the Construction of Sicilian Regionality», en Reid, H. L. - LeWIS, V. M. (eds.), Pindar in Sicily, Fonte Aretusa Organization, Parnassos Press, Sioux City, Iowa, pp. 195-220.

García Teijeiro, M. (1985a): «Escatología griega e Islas de los Bienaventurados», en Serta gratulatoria in honorem Juan Régulo, Universidad de La Laguna, La Laguna, pp. 271-280.

GarCía Teijeiro, M. (1985b): «Posibles elementos indoeuropeos en el Hades griego», en Melena, L. M. (ed.), Symbolae Ludovico Michelena septuagenario oblatae, vol. I, Universidad del País Vasco Instituto de Ciencias de la Antigüedad, Victoriaco Vasconvm - Salamanca, pp. 135-142.

Gazis, G. A. (2021): «Dying (?) in Pindar's Sicily: Olympian 2 and the Isle of the Blessed», en ReID, H. L LeWIS, V. M. (eds.),: Pindar in Sicily, Fonte Aretusa Organization, Parnassos Press, Sioux City, Iowa, pp. 97-118.

Gentili, B. - Bernardini, P. A. - Cingano, E. - Giannini, P. (1995): Pindaro. Le Pitiche, Fondazione Lorenzo Valla, Arnoldo Mondadori Editore, Milano.

Gentili, B. - Catenacci, C. - Giannini, P. - Lomiento, L. (2013): Pindaro. Le Olimpiche, Fondazione Lorenzo Valla, Arnoldo Mondadori Editore, Milano.

Giannini, 1995, vid. Gentili-Bernardini-Cingano-Giannini.

Giannini, 2013, vid. Gentili-Catenacci-Giannini-Lomiento.

Hobden, F. (2013): The Symposion in Ancient Greek Society and Thought, Cambridge University Press, Cambridge.

LeWIS, V. M. (2021): «Myth and Place in Pindar's Odes for Sicily», en ReID, H. L. - LeWIS, V. M. (eds.), Pindar in Sicily, Fonte Aretusa Organization, Parnassos Press, Sioux City, Iowa, pp. 1-10.

Lloyd-Jones, H. (1985): «Pindar and the After-Life», en Pindare, Entretiens sur l'Antiquité classique 31, Fondation Hardt, Genève, pp. 245-283.

Lomiento, 2013, vid. Gentili-CatenaCCi-Giannini-Lomiento.

Luraghi, N. (1994): Tirannidi arcaiche in Sicilia e Magna Grecia: da Panezio di Leontini alla caduta dei Dinomenidi, Leo S. Olschki, Firenze.

LuRAGHI, N. (1997): «Un mantis eleo nella Siracusa di Ierone: Agesia di Siracusa, Iamide di Stinfalo», Klio 79: 69-86.

MaCKIE, C. J. (ed.) (2004): Oral Performance and its Context, Brill, Leiden/Boston [Orality and Literacy in Ancient Greece, vol. 5].

Maclachlan, B. (2021): «Pindar and Sicilian Nymphs», en ReID, H. L. - Lewis, V. M. (eds.), Pindar in Sicily, Fonte Aretusa Organization, Parnassos Press, Sioux City, Iowa, pp. 31-50. 
Morgan, K. A. (2015): Pindar and the Construction of Syracusan Monarchy in the Fifth Century B. C., Oxford University Press, Oxford.

Morrison, A. D. (2007): Performances and Audiences in Pindar's Sicilian Victory Odes, Institute of Classical Studies, London.

MurraY, O. (1990): Sympotica. A symposion on the Symposion, Clarendon Press - Oxford University Press, Oxford - New York.

PòrtUlas, J. (1985): «La condition héroïque et le statut religieux de la louange», en Pindare, Entretiens sur l'Antiquité classique 31, Fondation Hardt, Genève, pp. 207-243.

Presutti, T. (2021): «Neither Hieron nor Theron: Herakles and Chromios in Pindar's Nemean 1», en ReID, H. L. - LeWIS, V. M. (eds.) (2021): Pindar in Sicily, Fonte Aretusa Organization, Parnassos Press, Sioux City, Iowa, pp. 179-194.

ReID, H. L. - LewIs, V. M. (eds.) (2021): Pindar in Sicily, Fonte Aretusa Organization, Parnassos Press, Sioux City, Iowa.

Romney, J. M. (2020): Lyric poetry and social identity in archaic Greece, University of Michigan Press, Ann Arbor.

Segal, C. (1998): Aglaia. The Poetry of Alcman, Sappho, Pindar, Bacchylides, and Corinna, Rowman \& Littlefield, Lanham (Md).

Sigelman, A. C. (2016): Pindar's Poetics of Immortality, Cambridge, Cambridge University Press.

Slater W. J. (1988): «Pindar's Pythian 3, Structure and Purpose» QUCC 29.2: 51-61.

SuÁrez de la Torre, E. (1988a): Pindaro. Obra completa, Letras Universales, Cátedra, Madrid.

SuÁreZ de la Torre, E. (1988b): «Adivinación y profecía en Píndaro (I)», Minerva 2: 65-106.

SuÁreZ de la Torre, E. (1989): «Adivinación y profecía en Píndaro (II)», Minerva 3: 79-119.

SuÁREZ DE LA TORRE, E. (1990): «Parole de poète, parole de prophète: les oracles et la mantique chez Pindare», Kernos 3: 347-358.

SuÁrez de la Torre, E. (1992): «Ixión y Arquíloco en la Pítica 2 de Píndaro», en Zaragoza, J. González Sanmartí, A., Homenatge à Josep Alsina (Actes del $X^{e}$ simpòsi de la Secciò Catalana de la SEEC, Tarragona, 28-30 november 1990), Tarragona, pp. 333-348.

SuÁrez de la Torre, E. (2006): «Les mentions généalogiques chez Pindare», Kernos 19: 97-111.

SuÁrez de la Torre, E. (2010): «El paisaje en Píndaro», en Montero, S. - Cardete, Ma C., Naturaleza y religión en el Mundo Clásico, Signifer Libros, Madrid, pp. 41-63.

SuÁrez de la Torre, E. (2013): «Apollo and Dionysus: Intersections», A. Bernabé et alii (eds.), Redefining Dionysus, De Gruyter, Berlin/Boston, pp. 58-81.

SuÁrez de la Torre, E. (2015): «The Apollonian Features of Pindar's Pythian Odes», en A. NASCIMENTO et alii (eds.), Revisitar o Mito - Myths Revisited, Humus, Ribeirão, pp. 11-30.

Vallet, G. (1985): «Pindare et la Sicile», en Pindare, Entretiens sur l'Antiquité classique 31, Fondation Hardt, Genève, pp. 285-327.

Velasco López, Ma H. (1996): El paisaje del Más Allá: el tema del prado verde en la escatología indoeuropea, Secretariado de Publicaciones e Intercambio Científico, Valladolid.

Vetta, M. (ed.) (1995²): Poesia e simposio nella Grecia Antica. Guida storica e critica, Laterza, Roma-Bari. WęCOwski, M. (2014): The Rise of the Greek Aristocratic Banquet, Oxford University Press, Oxford.

Young D. C. (1968): Three Odes of Pindar. A Literary Study of Pythian 11, Pythian 3, and Olympian 7 , Brill, Leiden. 